\title{
Operating Endoscopically with "Two Hands" to Remove Calcified Permanent Suture After Pyeloplasty
}

\author{
Sean McAdams, MD, Robert M. Sweet, MD, and James Kyle Anderson, MD
}

\begin{abstract}
We describe a combined percutaneous and endoscopic approach to remove encrusted permanent suture in the renal pelvis that was placed during pyeloplasty repair. Our index patient had a laparoscopic dismembered pyeloplasty at an outside institution 10 years before presenting with flank pain and nondependent nephrolithiasis. This proved to be an encrusted permanent suture material. There is limited data on incidence of nephrolithiasis after ureteropelvic junction repair, but it is well documented that nonabsorbable suture lines should be avoided in the urinary tract as they may serve as a nidus for stone formation.
\end{abstract}

\section{Clinical History}

A 30-YEAR-OLD FEMALE presented to us with 7 years of left flank discomfort that was worsening over the past several months. Her history was significant for left congenital ureteropelvic junction (UPJ) obstruction for which she underwent a laparoscopic dismembered pyeloplasty at an outside institution at age 20. Before our encounter, she underwent a CT scan that demonstrated left hydronephrosis and irregular calcifications at the left UPJ that were nongravity dependent (Fig. 1). The referring urologist did place a ureteral stent that provided relief of the patient's flank discomfort. She denies any history of urinary tract infections, hematuria, or kidney stones. She had no fevers or leukocytosis. Serum creatinine was normal and urine culture was negative.

\section{Physical Examination}

The patient had normal vital signs. She appeared healthy. Mild left flank tenderness was present, otherwise her physical examination was nonremarkable.

\section{Intervention}

The split-leg prone position was used to allow dual access to the renal collecting system by using a nephroscope through the flank and ureteroscope through a ureteral access sheath. ${ }^{1}$ Ultrasonic lithotripsy (CyberWand, Olympus) was first used for reduction of stone burden and to provide exposure of suture material (Fig. 2). Two surgeons then worked in synchrony, using a grasping instrument through the nephroscope to apply tension to the permanent suture material and permit transection through holmium: YAG laser lithotripsy at the level of the urothelium (Fig. 3). A $200 \mu \mathrm{m}$ laser fiber and laser settings of 0.3 Joules and $30 \mathrm{~Hz}$ were used for suture transection. Subsequently, a $500 \mu \mathrm{m}$ laser fiber was used through the nephroscope to obliterate any residual protrusions of suture material from the urothelium. A Double-J $26 \mathrm{~cm} \times 6 \mathrm{~F}$ ureteral stent was left postoperatively. Operative time was 3 hours and blood loss was $100 \mathrm{~mL}$.

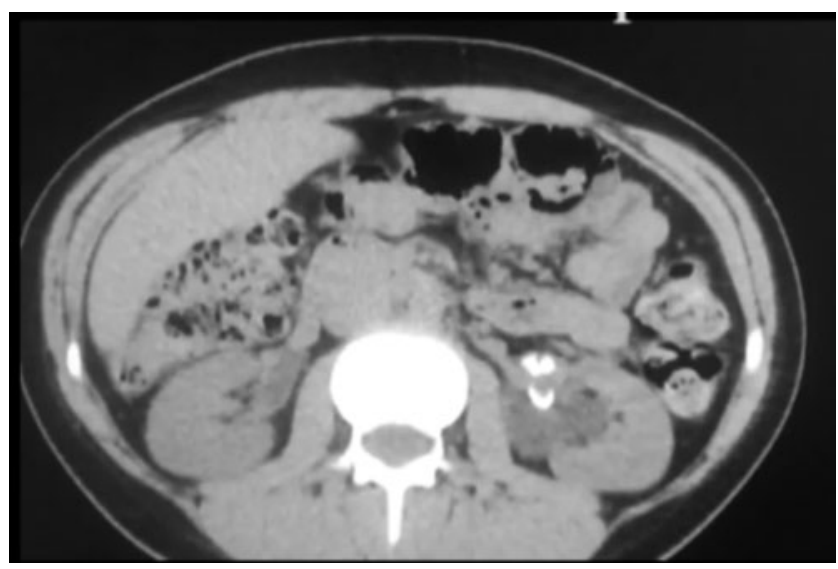

FIG. 1. Noncontrast CT demonstrating nongravitydependent calcifications at the left ureteropelvic junction with accompanying hydronephrosis.

Department of Urology, University of Minnesota, Minneapolis, Minnesota.

(C) Sean McAdams et al. 2016; Published by Mary Ann Liebert, Inc. This Open Access article is distributed under the terms of the Creative Commons License (http://creativecommons.org/licenses/by/4.0), which permits unrestricted use, distribution, and reproduction in any medium, provided the original work is properly credited. 


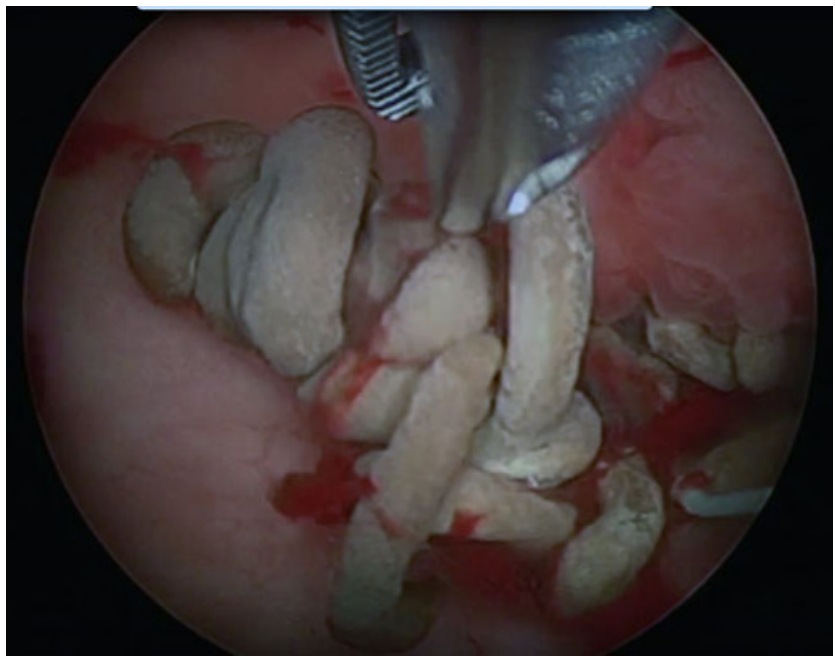

FIG. 2. Appearance of calcified sutures in left renal pelvis.

\section{Results}

The patient was visually stone free and all foreign suture material was removed from the renal pelvis. CT on postoperative day 1 was negative for residual stone and without abnormality. She was discharged the day after surgery and the ureteral stent was left in place for 2 weeks. Stone composition was $30 \%$ calcium oxalate and $70 \%$ calcium phos-

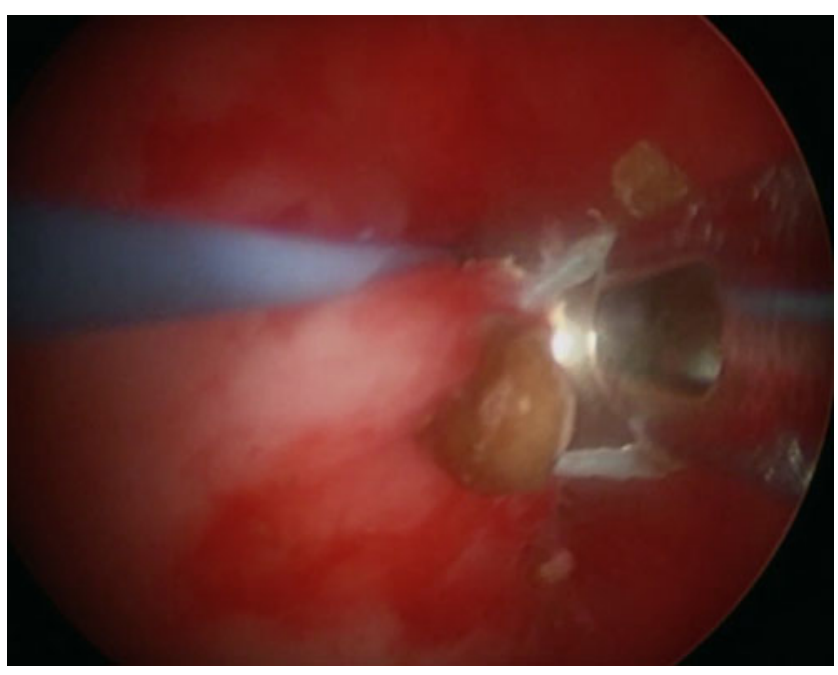

FIG. 3. Application of tension on the suture material through nephroscopy enables ureteroscopic transection of the foreign body at the level of the urothelium and eliminates the foreign body from future urine exposure. phate. The suture material was determined to be Ethibond, a nonabsorbable braided polyester suture. She was pain free at 6 months follow-up.

\section{Outcomes}

Nonabsorbable suture should not be used for reconstruction in the urinary tract, including pyeloplasty surgery, because it may serve as a nidus for future stone formation. One should consider foreign body a possible etiology for stone formation in patients with nondependent renal pelvis stones and previous pyeloplasty surgery. Removal of all foreign suture material from the collecting system is desired to reduce likelihood of recurrent stone formation. Endoscopic suture removal in the renal pelvis can be performed safely and effectively by using percutaneous access and the splitleg-prone position. The combined percutaneous and endoscopic approach allows operation with "two hands" within the urinary tract so that suture can be cut while on tension.

\section{Disclosure Statement}

No competing financial interests exist.

\section{Reference}

1. Khan F, BorinJF, Pearle MS, McDougall EM, Clayman RV. Endoscopically guided percutaneous renal access: "Seeing is believing." J Endourol 2006;20:451-455; discussion 455.

Address correspondence to: Sean McAdams, $M D$ Department of Urology University of Minnesota 420 Delaware St. SE, MMC 394 Minneapolis, MN 55455

E-mail: mcadams.sean@mayo.edu

\begin{tabular}{|c|}
\hline Abbreviations Used \\
$\mathrm{CT}=$ computed tomography \\
$\mathrm{UPJ}=$ ureteropelvic junction
\end{tabular}

Cite this article as: McAdams S, Sweet RM, Anderson JK (2016) Operating endoscopically with "two hands" to remove calcified permanent suture after pyeloplasty, Journal of Endourology Case Reports 2:1, 1-2, DOI: $10.1089 /$ cren.2015.0031. 